\title{
Bacharelado em Educação Física: qual o entendimento de alunos concluintes em relação ao fenômeno corpo/ corporeidade?
}

\author{
Bachelor degree in physical education: what are the undergraduate \\ final students understanding the body/corporeality phenomenon?
}

\author{
Rafael Guimarães Botelho ${ }^{1}$ (D; Weisiana Santana de Castro Paiva ${ }^{2}$ (D); Wagner \\ Wey Moreira 2,3 (1) \\ ${ }^{1}$ Instituto Federal de Educação, Ciência e Tecnologia do Rio de Janeiro (IFRJ); ${ }^{2}$ Univer- \\ sidade Federal do Triângulo Mineiro (UFTM); ${ }^{3}$ Bolsista de Produtividade em Pesquisa, \\ CNPq, Brasil.
}

\begin{abstract}
Resumo
Este artigo, que versa sobre o fenômeno corpo/corporeidade, teve por objetivo geral identificar, por meio do discurso de alunos concluintes, qual o sentido de corpo e como este aluno exercita sua ação profissional junto ao seu aluno/cliente. Esta pesquisa fenomenológica, que empregou a técnica de elaboração e análise de unidades de significado, utilizou uma entrevista com duas perguntas: 1a) O que é corpo para você?; e 2ª) Como você exercita sua ação profissional junto ao aluno/cliente no desenvolvimento dos conteúdos aprendidos no Curso de Graduação? Participaram deste estudo 29 alunos concluintes de um Bacharelado em Educação Física. A partir da análise dos discursos da Pergunta 1 , foram estabelecidas nove unidades de significado, e a com maior incidência foi "O corpo como Estrutura anatomofisiológica" (24,13\%). Em relação à Pergunta 2, foram identificadas sete unidades de significado, sendo a principal a "De acordo com o aprendido no curso universitário" (48,27\%). Em substância, o sentido de corpo, no entendimento da maioria dos alunos concluintes, é calcado numa visão tradicional e no modelo cartesiano, com ênfase no paradigma biologicista e visão mecanicista.
\end{abstract}

Palavras-chave: corpo; corporeidade; alunos concluintes; bacharelado em Educação Física.

\begin{abstract}
This paper, which deals with the body/corporeality phenomenon, had the general aim of identifying, through the discourse of undergraduate final students, what the meaning of the body is and how this undergraduate students exercises his professional action with his student/client. This phenomenological research, which used the technique of elaboration and analysis of units of meaning, used an interview with two questions: 1a) What is body for you?; and 2a) How do you exercise your professional action with the student/client in the development of the content learned in the Undergraduate Course? 29 undergraduate final students participated in this study. From the analysis of the speeches in Question 1, nine units of meaning were established, and the one with the highest incidence was "The body as an anatomophysiological structure" (24.13\%). In relation to Question 2, seven units of meaning were identified, the main one being the unit "According to what was learned in the university course" (48.27\%). In essence, the sense of body, in the understanding of most undergraduate final students, is based on a traditional view and the Cartesian model, with an emphasis on the biologicist paradigm and a mechanistic view.
\end{abstract}

Keywords: body; corporeality; undergraduate final students; degree in Physical Education.

Como citar (APA):

Botelho, R. G., Paiva, W. S. de C. \& Moreira, W.W. (2021). Bacharelado em Educação Física: qual o entendimento de alunos concluintes em relação ao fenômeno corpo/corporeidade?. Revista Iberoamericana de Educación, 85(2),27-52. https://doi.org/10.35362/rie8523938 


\section{Introdução}

No Brasil, a partir dos anos oitenta do Século XX, alguns professores e pesquisadores da Educação, da Educação Física e do Esporte repensaram o sentido hegemônico de corpo presente na área, e, apoiados em referenciais das Ciências Humanas e Sociais, insurgiram-se contra o sentido de "corpomáquina" dominante neste universo. Dentre esses profissionais, destacam-se Medina (1987, 2001), Morais (2014), Moreira (1995, 2019), Oliveira (1987), Santin (2014), Silva (1987) e outros que elaboraram escritos na trilha do entendimento de um corpo humano e humanizado, substituindo o trato mecânico e fragmentado do corpo por uma atuação pautada na união de intelecto, sensibilidade, unidade e possibilidade de transcendência corporal.

Em face do supracitado período de transição, muitas outras publicações foram desenvolvidas enfocando o fenômeno corporeidade, registrando-se aqui apenas alguns autores que atuam na área da Educação Física e dos Esportes, como, por exemplo, Gallo (2006), Gallo e Zeppini (2016), Inforsato (2006), Moreira e Simões (2016) e Nóbrega (2010), constituindo-se, já no Século XXI, uma ampla produção sobre o assunto.

Igualmente, é a partir da década de oitenta do Século XX que se estabelecem os Cursos de Bacharelado para a área da Educação Física no Brasil, por meio da Resolução n- 03/1987 (Conselho Federal de Educação, 1987), ainda que alguns cursos tenham sido criados antes da referida resolução, como foi, em 1985, o Bacharelado em Técnicas Desportivas da Universidade Estadual de Campinas (UNICAMP).

O Bacharelado ${ }^{1}$ em Educação Física, no contexto brasileiro, é um tipo de curso que forma um profissional para atuar em vários campos da Educação Física e do Desporto, mas que não pode atuar na escola (somente o licenciado em Educação Física é que pode ministrar aulas na escola). Na área da Educação Física as legislações brasileiras que regulam este curso são a Resolução ${ }^{\circ}$ 7, de 31 de março de 2004 (Conselho Nacional de Educação, 2004), que

\footnotetext{
${ }^{1}$ A título de esclarecimento, o vocábulo "Bacharelado" não pode ter tradução literal à língua castelhana. Na Espanha, local de publicação da Revista Iberoamericana de Educación $(R I E)$, a denominação oficial deste tipo de curso na área da Educação Física é Grado en Ciencias de la Actividad Física y del Deporte (España, 2018).
} 
inclui uma alteração - a Resolução n 7, de 4 de outubro de 2007 (Conselho Nacional de Educação, 2007), e a Resolução n- 6, de 18 de dezembro de 2018 (Conselho Nacional de Educação, 2018).

Portanto, do período de criação do Bacharelado até os dias atuais, prosperaram as instituições que oferecem este tipo de curso na área da Educação Física. Pode-se, inclusive, afirmar que em todas as regiões do Brasil é possível identificar estes cursos. Por um lado, são muitos os alunos concluintes; por outro, são ainda incipientes as pesquisas que procuram verificar o entendimento destes alunos sobre o fenômeno corpo/corporeidade. Com base neste quadro, algumas questões ainda permanecem sem respostas:

- Qual a compreensão de corpo por parte de um aluno concluinte de Bacharelado em Educação Física?

- O entendimento de corpo estaria associado, em sua maioria, à visão mecanicista e ao paradigma biologicista?

Todo este contexto justifica a construção deste artigo, cujo objetivo geral é identificar, por meio do discurso de alunos concluintes, qual o sentido de corpo e como este aluno concluinte exercitará sua ação profissional junto ao seu aluno/cliente. Para auxiliar este escopo, foram traçados os seguintes objetivos específicos: (a) analisar a existência de uma possível concepção dualista de corpo/mente nos discursos dos alunos concluintes do Curso de Bacharelado em Educação Física; e (b) verificar quais são os pontos de convergência e de divergência nos discursos dos alunos concluintes.

A razão para selecionar neste estudo o aluno concluinte (que é aquele que está no último ano do curso) fundamenta-se no fato de este já estar cursando o estágio e, igualmente, ter finalizado a maioria das disciplinas da matriz curricular do curso, o que lhe permite, em teoria, ter uma visão consolidada sobre o objeto de estudo desta pesquisa: o corpo.

\section{Bases teóricas: do corpo à corporeidade}

Uma das formas sinalizadas para a superação do entendimento do corpo como máquina na Educação Física e nos Esportes empregada pelos autores já mencionados tem como pressuposto a base epistemológica da Fenomenologia, em especial, nos escritos de Merleau-Ponty (1990, 1991, 2004, 2007, 2018). 
A ênfase a essa necessidade de mudança no trato com o corpo pode ser evidenciada pela argumentação de Gallo (2006), quando deseja que a área possa permitir: "Resistência à educação que recebemos, prática disciplinar e biopolítica de controle que nos leva ao corpo superexcitado, supermalhado, hiperativo" (p. 29).

Seguindo a mesma concepção epistemológica, Moreira e Simões (2016) afirmam que nossa existencialidade biológica, social e histórica só se concretiza via corpo numa vivência "[...] entre permissões e proibições de toda natureza: regras, normas, controles, diferentes abordagens elaboradas por teorias científicas, artísticas, filosóficas e pedagógicas [...]" (p. 137), e isto exige um redimensionamento do entendimento do ser humano, que é corpóreo.

Nóbrega (2010) recorda que a corporeidade "[...] emerge da capacidade interpretativa do ser vivo desde os níveis celulares e moleculares até os aspectos simbólicos e sociais" (p. 35). Isto, sem dúvida, propicia um saber incorporado, permitindo a associação das estruturas intelectuais e sensíveis do ser humano.

Caminha (2019, p. 65) vai mais longe, referindo-se a esse momento de transição do entendimento e do trato do corpo máquina para o acolhimento do corpo sensível e que busca transcendência, informando: "A Educação Física que morre e a que nasce em mim é pensada a partir do corpo próprio e da carne em Merleau-Ponty [...]" e isso possibilita a "[...] construção de uma cosmovisão que integram campo de conhecimento científico, prática pedagógica e ações de transformação social" (p. 65).

Já Santin (2014), ao declarar que as ciências modernas não deram a devida atenção ao corpo, pois aplicam a este os conhecimentos advindos do desenvolvimento de pesquisas em animais, confere o sentido de máquina ao corpo humano, fato esse também constatado no âmbito da área de Educação Física, estando aí presentes as valorizações da bioquímica e da biomecânica, sempre no sentido de melhorar o rendimento atlético. Daí a necessidade de alteração deste quadro, levando-nos a considerar uma corporeidade cultuada e cultivada. Insiste o autor nessa trilha, encerrando seu artigo com: "A educação física repensada para cultivar e cultuar a corporeidade humana precisará inspirar-se no impulso sensível, na harmonia musical, nos ideais de beleza e nos valores estéticos" (p. 68). 
Morais (2014) é mais um autor que enfatiza as duas alternativas presentes para a concepção de corpo e para a ação de profissionais da corporeidade, incluído aqui os da Educação Física, dizendo que estes podem entender "[...] o corpo como se este fora simples coisa burra que se adestra ou despertam para o fato de sermos um corpo como forma de estar-no-mundo sensível e inteligentemente" (p. 84).

E por que todos esses autores, e outros mais ainda, debruçam-se a entender a corporeidade em sua facticidade no mundo? Por que advogam a passagem, no universo da Educação Física, do trato com o corpo mecânico e esquartejado, para assumi-lo como corporeidade em toda sua complexidade?

Uma das possíveis respostas a estas indagações pode ser encontrada nas palavras de Merleau-Ponty (2018, p. 14): "O mundo é não aquilo que eu penso, mas aquilo que eu vivo; eu estou aberto ao mundo, comunico-me indubitavelmente com ele, mas não o possuo, ele é inesgotável". Ser corporeidade é estar no mundo executando movimentos, explicitando nossa motricidade.

\section{Orientações metodológicas}

\subsection{Natureza do estudo}

Este estudo, de natureza fenomenológica, busca identificar o entendimento do fenômeno corpo/corporeidade presente no discurso de alunos concluintes de um Curso de Bacharelado em Educação Física. Na pesquisa fenomenológica a análise do fenômeno "[...] vai do constituído (realidade concreta) ao constituinte (essência)" (Bruyne, Herman \& Schoutheete, 1991, p. 75). Por conseguinte, nesta pesquisa adota-se a concepção de Fenomenologia proposta por Merleau-Ponty (2018, p. 1, grifo do autor):

A fenomenologia é o estudo das essências, e todos os problemas, segundo ela, resumem-se em definir essências: a essência da percepção, a essência da consciência, por exemplo. Mas a fenomenologia é também uma filosofia que repõe as essências na existência, e não pensa que se possa compreender o homem e o mundo de outra maneira senão a partir de sua "facticidade". 


\subsection{Técnica de análise}

Este estudo empregou a técnica de Elaboração e Análise de Unidades de Significado (Moreira, Simões \& Porto, 2005). Trata-se de uma técnica de análise qualitativa, combinação da Análise de Asserção Avaliativa (Bardin, 1977) com a Análise do Fenômeno Situado (Giorgi, 1978; Martins \& Bicudo, 1989), e que reúne conceitos provenientes da pesquisa fenomenológica.

A técnica de elaboração e análise de unidades de significado é realizada em três momentos: 1) Relato ingênuo, 2) Identificação das atitudes e 3) Interpretação.

1. Relato ingênuo. É o momento em que o pesquisador, em primeiro lugar, esclarece o porquê da pesquisa aos participantes, e, após isto, aplica as questões geradoras, cujo objetivo é registrar "[...] os dizeres dos sujeitos na sua forma original, sem alterar a grafia ou substituir termos por outros equivalentes. É o discurso em sua vertente 'pura', não sofrendo neste momento nenhum tipo de polimento ou modificação" (Moreira, Simões \& Porto, 2005, p. 111).

2. Identificação das atitudes. Os pesquisadores efetuaram várias leituras dos relatos ingênuos (dos participantes da pesquisa) e, a partir disto, foram identificados os indicadores mais relevantes destes discursos (Quadros 1 e 2). Logo, a partir da análise do quadro de indicadores, foram selecionadas as unidades mais significativas (Tabelas 2 e 3) presentes nos discursos dos participantes.

3. Interpretação. "Com o quadro geral das idéias de cada sujeito montado e caracterizado pela identificação das unidades de significado, bem como as convergências e divergências [identificadas nos discursos], o pesquisador passa a fazer a análise interpretativa do fenômeno, buscando compreendê-lo em sua essência [...]" (Moreira, Simões \& Porto, 2005, p. 111). Dito de outra forma, os pesquisadores, com o auxílio das unidades de significado, buscaram pontos de convergência e de divergência nos discursos dos participantes para, a partir disto, compreender a essência do fenômeno analisado.

\subsection{Instrumento de pesquisa}

O instrumento adotado foi uma entrevista que incluiu duas perguntas: 1a) $\mathrm{O}$ que é corpo para você?; e 2a) Como você exercita sua ação profissional junto ao aluno/cliente no desenvolvimento dos conteúdos aprendidos no Curso de Graduação? 


\subsection{Local da pesquisa}

O presente estudo foi realizado em uma instituição de ensino superior (IES) particular na região do Triângulo Mineiro, no Estado Minas de Gerais. O curso analisado foi um Bacharelado em Educação Física, oferecido no horário noturno.

\subsection{Coleta de dados}

A coleta de dados foi realizada em 21 de novembro de 2018, à noite, sendo as perguntas respondidas pelos alunos, individualmente, em sala de aula.

A aplicação da entrevista realizou-se utilizando as seguintes orientações: (a) Garantia de anonimato: foi asseverado aos 29 participantes que eles não serão identificados; (b) Foi esclarecido o objetivo da pesquisa. Após esta etapa, foi mencionado aos participantes que as respostas podem conter o máximo de informações possíveis, não existindo respostas corretas ou incorretas, oferecendo-se, desta forma, o tempo necessário para a resposta de cada participante; (c) Foi apresentado e esclarecido o Termo de Consentimento Livre e Esclarecido (TCLE), e, em seguida, ele foi preenchido e assinado por cada participante da pesquisa; (d) Ordem para as respostas: primeiro, foi oferecida ao participante a primeira folha, que continha a primeira pergunta. Após a resposta da primeira pergunta, foi disponibilizada a segunda folha, que incluía a segunda pergunta. Após a resposta da segunda pergunta, todas as folhas foram recolhidas pelos pesquisadores.

\subsection{Participantes da pesquisa}

Alguns critérios de inclusão foram estabelecidos para os participantes:

a) Ser aluno concluinte, em 2018, do Bacharelado em Educação Física.

b) Assinar o TCLE.

c) Responder a duas perguntas geradoras presentes no instrumento de pesquisa.

A seguir, a Tabela 1 descreve algumas características dos participantes da pesquisa: quantidade, sexo, idade e formação. 
Tabela 1. Características dos participantes da pesquisa

\begin{tabular}{|c|c|c|c|}
\hline Número & Sexo & Idade & $\begin{array}{l}\text { Formação completa em } \\
\text { Educação Física }\end{array}$ \\
\hline 01 & Masculino & 34 & Não \\
\hline 02 & Masculino & 23 & Não \\
\hline 03 & Masculino & 34 & Licenciado \\
\hline 04 & Feminino & 23 & Não \\
\hline 05 & Masculino & 29 & Não \\
\hline 06 & Masculino & 22 & Não \\
\hline 07 & Feminino & 22 & Não \\
\hline 08 & Masculino & 24 & Não \\
\hline 09 & Feminino & 20 & Não \\
\hline 10 & Masculino & 25 & Não \\
\hline 11 & Feminino & 21 & Não \\
\hline 12 & Feminino & 20 & Não \\
\hline 13 & Masculino & 24 & Não \\
\hline 14 & Masculino & 22 & Licenciado \\
\hline 15 & Masculino & 33 & Não \\
\hline 16 & Masculino & 26 & Não \\
\hline 17 & Masculino & 24 & Não \\
\hline 18 & Masculino & 22 & Licenciado \\
\hline 19 & Feminino & 22 & Não \\
\hline 20 & Feminino & 39 & Não \\
\hline 21 & Feminino & 20 & Não \\
\hline 22 & Masculino & 29 & Não \\
\hline 23 & Feminino & 27 & Não \\
\hline 24 & Masculino & 24 & Não \\
\hline 25 & Masculino & 23 & Não \\
\hline 26 & Feminino & 23 & Não \\
\hline 27 & Masculino & 21 & Não \\
\hline 28 & Masculino & 36 & Não \\
\hline 29 & Feminino & 27 & Não \\
\hline
\end{tabular}

Fonte: elaboração própria.

A referida tabela assinala as seguintes características: (a) foram 29 participantes da pesquisa; (b) 18 participantes eram homens; (c) 11 participantes eram mulheres; (d) os participantes tinham entre 20 e 39 anos, com uma média de 25,48 anos; (e) dos 29 alunos concluintes, três tinham licenciatura em Educação Física. 
Este estudo foi realizado por pesquisadores e colaboradores do Núcleo de Estudos e Pesquisas em Corporeidade e Pedagogia do Movimento (NUCORPO), sendo, consequentemente, vinculado a uma pesquisa maior (Projeto CAAE: 50087115.6.0000.5154), aprovada pelo Comitê de Ética em Pesquisa (CEP) da Universidade Federal do Triângulo Mineiro (UFTM).

\section{Resultados}

Nesta seção, apresenta-se a análise ideográfica (que descreve as ideias individuais de cada participante da pesquisa), além de se estabelecer as unidades de significado dos discursos.

\subsection{Análise ideográfica da Pergunta 1}

Após a leitura das respostas da Pergunta 1, foi identificado um conjunto de indicadores, descrito no Quadro 1.

Quadro 1. Análise ideográfica da Pergunta 1: O que é corpo para você?

\begin{tabular}{|c|c|}
\hline \multicolumn{2}{|r|}{ Bacharelado em Educação Física } \\
\hline Participantes & Indicadores \\
\hline 1 & $\begin{array}{l}\text { É físico, palpável. } \\
\text { Expressa sentimentos. } \\
\text { É uma obra-prima criada por (Deus). }\end{array}$ \\
\hline 2 & É um reflexo de uma personalidade. \\
\hline 3 & $\begin{array}{l}\text { É a morada da nossa alma, do nosso espírito. } \\
\text { Abriga os nossos órgãos. }\end{array}$ \\
\hline 4 & Uma máquina fantástica de estímulos e respostas. \\
\hline 5 & É o meu cartão de visita. \\
\hline 6 & $\begin{array}{l}\text { É uma máquina composta por organismos, membros interligados, } \\
\text { estruturado... }\end{array}$ \\
\hline 7 & É um meio de você se expressar. \\
\hline 8 & $\begin{array}{l}\text { É a morada do meu espírito, é uma estrutura sagrada que Deus } \\
\text { nos proporcionou para a evolução espiritual. }\end{array}$ \\
\hline 9 & $\begin{array}{l}\text { É um instrumento de uso do ser humano. } \\
\text { Dependência dos afazeres do dia a dia. } \\
\text { Arte. } \\
\text { Estética. }\end{array}$ \\
\hline 10 & É uma obra-prima criada por Deus. \\
\hline 11 & É uma "máquina”. \\
\hline
\end{tabular}




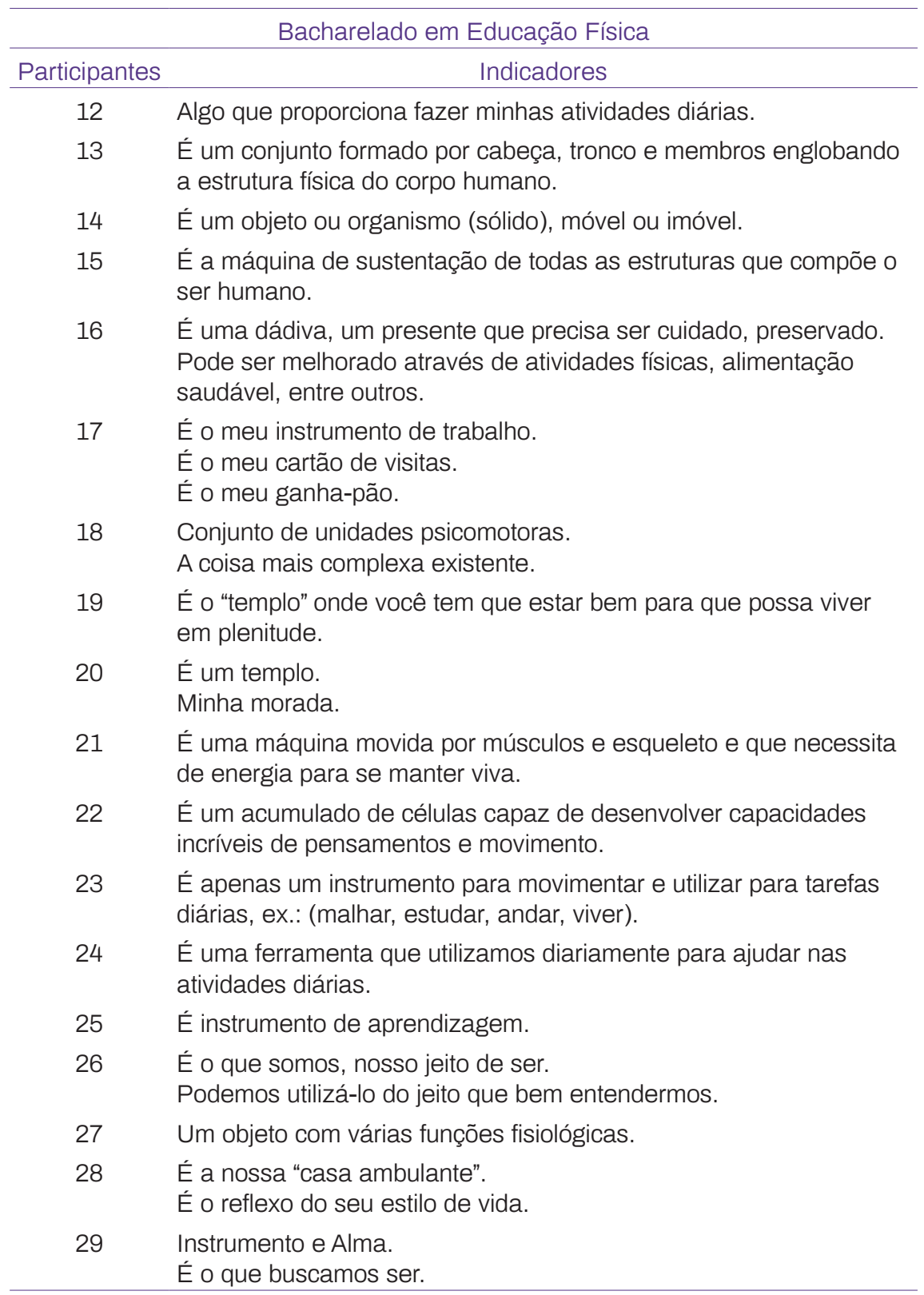

Fonte: elaboração própria.

A partir da análise ideográfica, foram estabelecidas nove unidades de significado, expostas na Tabela 2, e que mostram, sem necessidade de generalizações, os pontos de convergência e de divergência nos discursos. 


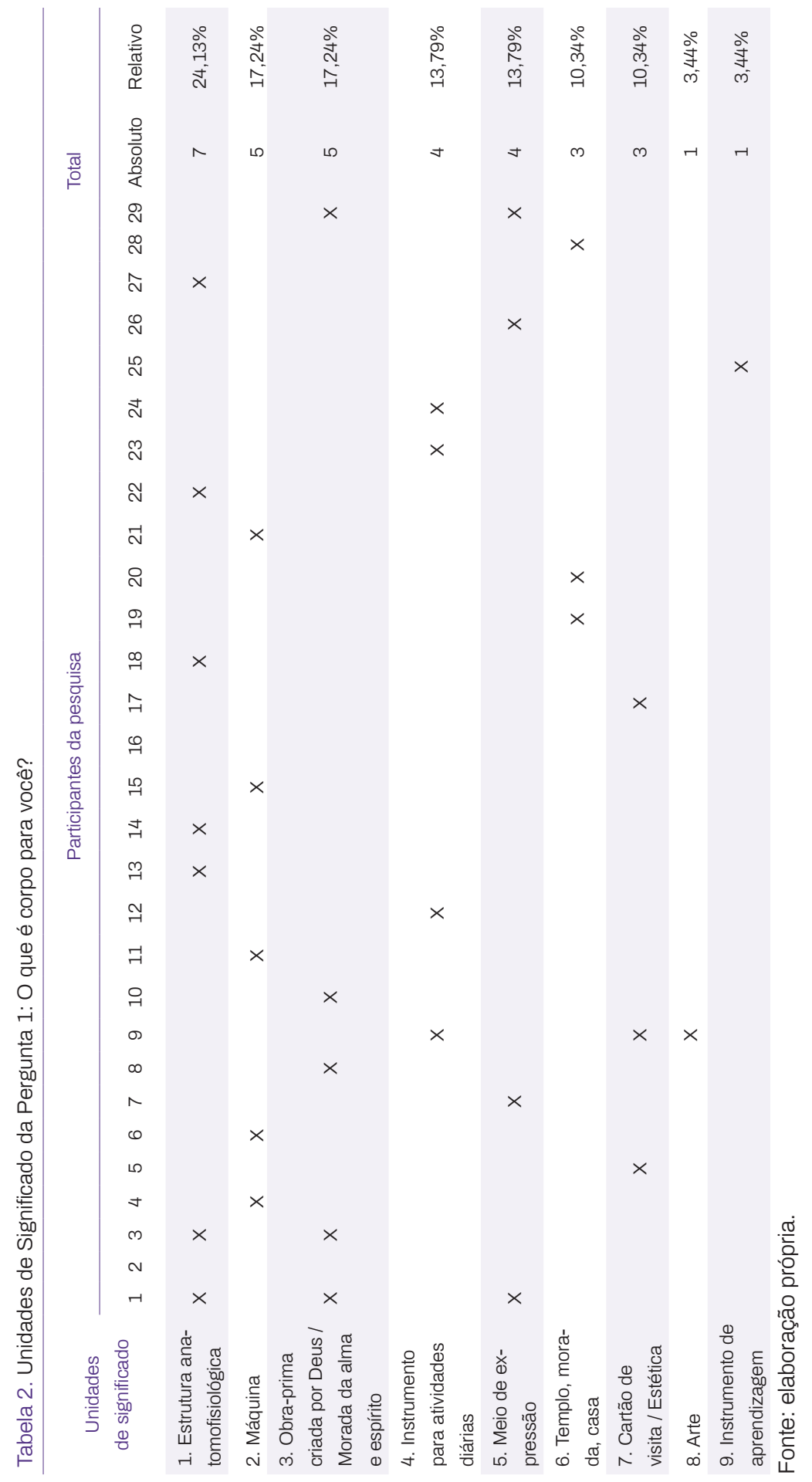




\subsection{Análise ideográfica da Pergunta 2}

Após a leitura das respostas da Pergunta 2, foram elaborados vários indicadores, expostos no Quadro 2.

Quadro 2. Análise ideográfica da Pergunta 2: Como você exercita sua ação profissional junto ao aluno/cliente no desenvolvimento dos conteúdos aprendidos no Curso de Graduação?

\begin{tabular}{|c|c|}
\hline \multicolumn{2}{|r|}{ Bacharelado em Educação Física } \\
\hline Participantes & Indicadores \\
\hline 1 & $\begin{array}{l}\text { Anatomia, fisiologia, postura. } \\
\text { Com entusiasmo. }\end{array}$ \\
\hline 2 & Vivendo um estilo de vida que os alunos desejam ter. \\
\hline 3 & $\begin{array}{l}\text { Ainda não estou trabalhando na área. } \\
\text { Ética. } \\
\text { Respeito. } \\
\text { Consciência. }\end{array}$ \\
\hline 4 & $\begin{array}{l}\text { Através de repasse de ensinamentos. } \\
\text { Eu ensino, mas também aprendo muito, ou seja, vivo sempre em } \\
\text { constante aprendizagem. }\end{array}$ \\
\hline 5 & Transmitir da melhor maneira possível tudo o que eu aprendi aqui. \\
\hline 6 & Ainda não atuo na área. \\
\hline 7 & $\begin{array}{l}\text { Ajudando nos seus objetivos. } \\
\text { Dando bronca se possível. }\end{array}$ \\
\hline 8 & $\begin{array}{l}\text { De uma forma responsável. } \\
\text { Objetivando o resultado que o aluno (cliente) procura. } \\
\text { Alertando sempre para eventuais riscos ou lesões. }\end{array}$ \\
\hline 9 & Através das aulas que tive na Faculdade. \\
\hline 10 & $\begin{array}{l}\text { Mesmo com todo conhecimento adquirido, a maior parte vem na } \\
\text { vivência durante as aulas e fazendo outros cursos. }\end{array}$ \\
\hline 11 & $\begin{array}{l}\text { Ética } \\
\text { De acordo com os conteúdos aprendidos. } \\
\text { Para que ele alcance o resultado desejado. } \\
\text { Segurança. }\end{array}$ \\
\hline 12 & $\begin{array}{l}\text { Conforme vou aprendendo tento desenvolver da melhor maneira } \\
\text { possível. }\end{array}$ \\
\hline 13 & Com Ética. \\
\hline 14 & $\begin{array}{l}\text { Utilizo todo o conhecimento e o pratico para a promoção estética e } \\
\text { saudável do aluno. }\end{array}$ \\
\hline 15 & $\begin{array}{l}\text { De forma enérgica. } \\
\text { Da mesma que aprendi na graduação. }\end{array}$ \\
\hline
\end{tabular}




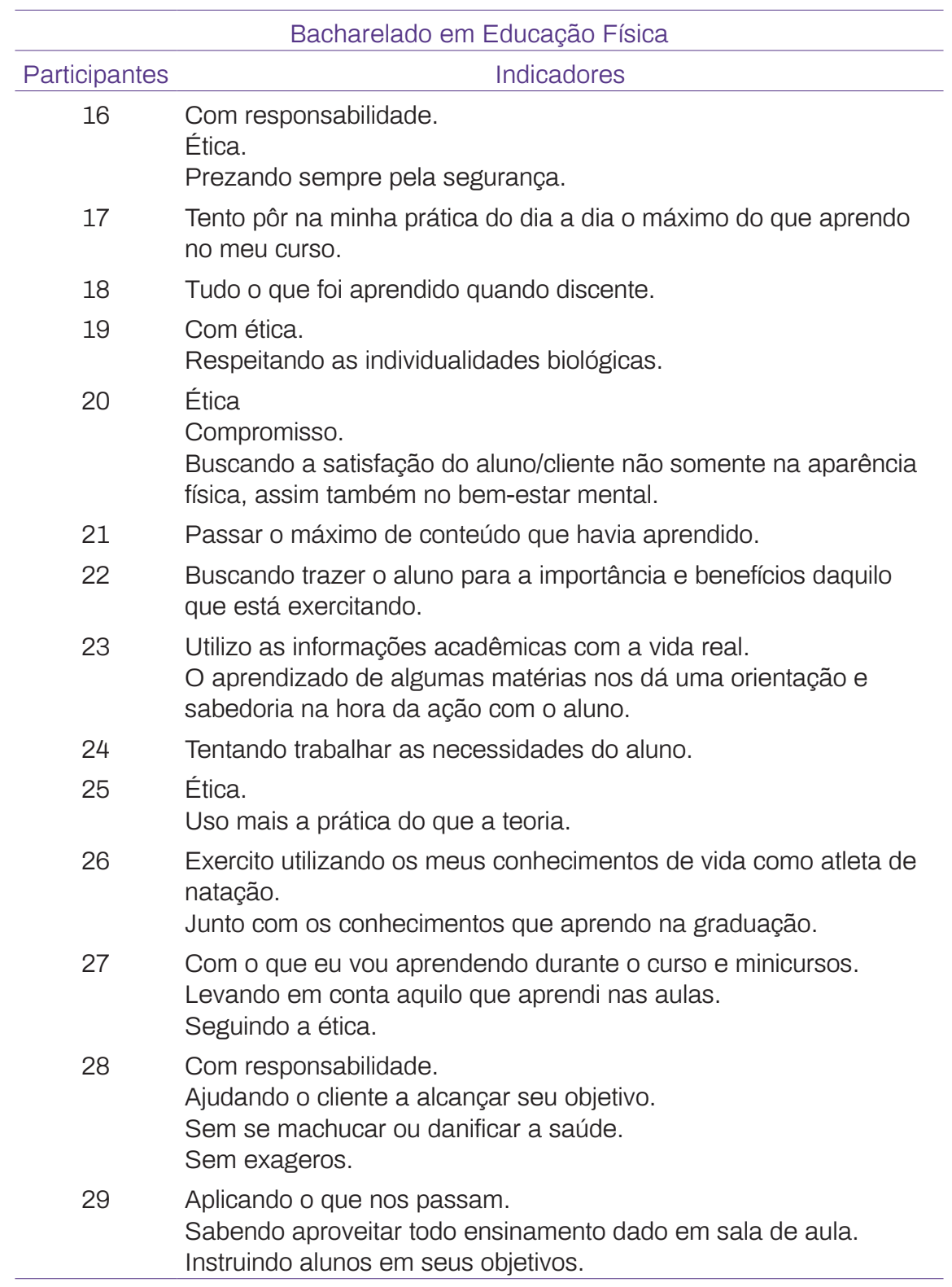

Fonte: elaboração própria.

Com base na análise ideográfica, foram elaboradas sete unidades de significado, reunidas na Tabela 3, e que ilustram os pontos de convergência e de divergência nos discursos dos participantes. 


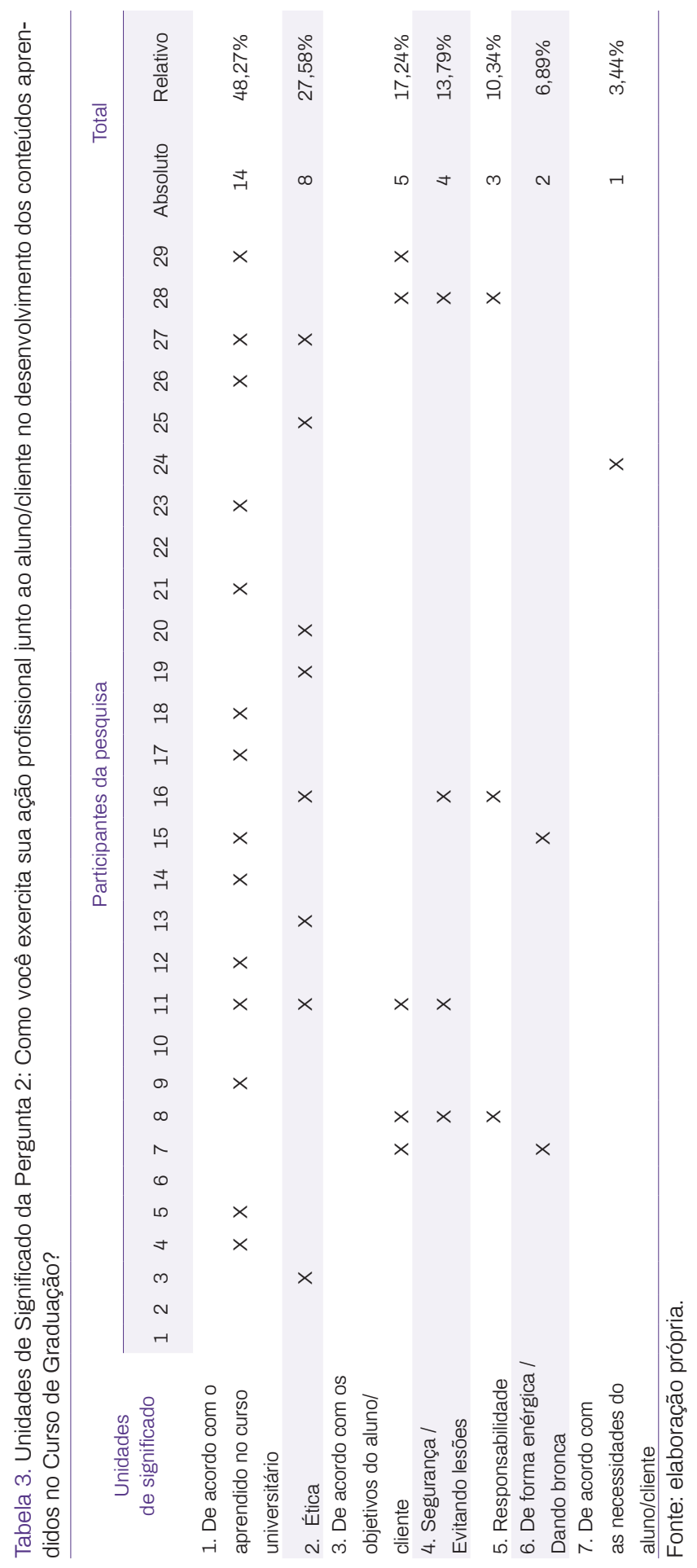




\title{
5. Discussão
}

\subsection{Discussão da Pergunta 1}

Um primeiro ponto a ser observado diz respeito ao quantitativo estabelecido nas unidades de significado. A soma deste quantitativo não tem o percentual de 100, já que as respostas presentes nos discursos podem estar incluídas em mais de uma unidade de significado, como é, por exemplo, o Participante 1, que apresentou um discurso computado em três unidades de significado.

\section{O corpo como "Estrutura anatomofisiológica"}

A primeira unidade de significado com maior ocorrência é a compreensão de corpo como uma "Estrutura anatomofisiológica". Fica patente que o discurso dos alunos concluintes é influenciado por disciplinas como Anatomia Humana e Fisiologia Humana, presença biológica nos cursos de Bacharelado em Educação Física. A título de ilustração, observe-se o que proferiu o Participante 13: "É um conjunto formado por cabeça, tronco e membros englobando a estrutura física do corpo humano". Trata-se, portanto, de um discurso essencialmente anatômico.

Disciplinas como Anatomia Humana e Fisiologia Humana são fundamentais, não há dúvida sobre isso, mas a compreensão de corpo, pelo futuro profissional de Educação Física, não pode se limitar a estes conteúdos.

\begin{abstract}
Historicamente, o corpo do ser humano tem sido visto e tratado preferencialmente do ponto de vista da sua anatomia e da sua fisiologia. Nesta ótica, o que se procura transmitir aos educadores interessados na melhoria do corpo e na utilidade de seus movimentos é um corpo humano no seu aspecto físico, em suas formas, na tonicidade de seus músculos e na explicação dos movimentos coordenados desse corpo. Isto faz com que, ao longo desse processo, haja a transformação do corpo, que deveria ser considerado veículo do ser-no-mundo em um dos objetos componentes desse mundo. "Coisificamos" o corpo. Desprezamos a experiência do corpo e privilegiamos a idéia de corpo (Moreira, Simões \& Porto, 2005, p. 108, grifo dos autores).
\end{abstract}

\section{O corpo como "Máquina"}

A segunda maior incidência nos discursos dos participantes atrela corpo à máquina. Os Participantes 4, 6, 11, 15 e 21 afirmam que corpo é uma máquina. Para a Participante 4, corpo é "uma máquina fantástica de estímulos e respostas". 
A ideia de "corpo como máquina" é encontrada em outros estudos (Aranda, Pereira, Palma \& Palma, 2012; Souza, Schmidt, Santo \& Montalvão, 2011), independentemente do tipo de curso. Por exemplo, Souza et al. (2011, p. 7), que investigaram a percepção de corpo de 19 alunos do oitavo período de um Bacharelado em Educação Física de uma instituição particular de Goiânia, identificaram "[...] que 59\% dos entrevistados idealizam seu corpo para o máximo de rendimento (corpo máquina), contra $41 \%$ que optam pelo corpo saudável (corpo sujeito)".

Agora no âmbito da licenciatura, uma das conclusões de Aranda et al. (2012), que analisaram o discurso de 15 discentes de Educação Física da Universidade Estadual de Londrina (UEL) (nove da Licenciatura Generalista e seis da Licenciatura Atual), foi a seguinte: "Numa perspectiva macro, verificou-se que no currículo Licenciatura Generalista: 04 estudantes aproximaram-se mais de uma concepção de corpo dualista, corpo máquina, marcado pela fragmentação abissal e pela divisão entre o corporal e o mental [...]" (p. 745), um quantitativo que reforça a concepção de "corpo máquina" como ideia recorrente na formação inicial em Educação Física.

Em oposição à ideia de máquina, considera-se fundamental compreender o corpo em sua amplitude:

Depende de nós, agindo politicamente, ou que não haja nenhum homemmáquina, ou que ele seja tão amável quanto o homem de lata do Mágico de $\mathrm{Oz}$, que acaba ganhando um coração no final da jornada. É o homem como autor do seu destino, suficientemente corajoso para rejeitar qualquer apelo a um pai transcendente, suficientemente humanista para não transformar a pedagogia em arte de amestrar, e suficientemente democrático para não substituir a política pela biologia (Rouanet, 2003, p. 62, grifo do autor).

\section{O corpo como "Obra-prima criada por Deus / Morada da alma e espírito"}

Ainda com a segunda maior prevalência, a visão do corpo por meio da religião é algo presente em cinco discursos. O Participante 3 expressa: "É a morada da nossa alma, do nosso espírito, sendo de suma importância para a nossa existência, ou seja, nossa vida. O corpo abriga os nossos órgãos, ele é responsável por nós realizarmos as nossas atividades, desde uma simples fala, um caminhar, um pensar, respirar, cheirar, ouvir e até mesmo realizarmos atividades mais complexas. Precisamos cuidar muito bem dele!!!". Contata-se, neste discurso, uma divergência, já que o participante afirma que 
o corpo abriga os nossos órgãos. Já o Participante 8 é direto em relação à dimensão divina: "É a morada do meu espírito, é uma estrutura sagrada que Deus nos proporcionou para a evolução espiritual".

\section{O corpo como "Instrumento para atividades diárias"}

O utilitarismo corporal pode ser observado em quatro discursos. À guisa de exemplo, observe-se o que disse a Participante 9: "É um instrumento de uso do ser humano, arte, estética, dependência dos afazeres do dia a dia". Por sua vez, a Participante 23 expressa: "É o instrumento que utilizamos para fazer nossas tarefas diárias. O corpo é um instrumento que se vive, e sente, hoje, a ideologia e o modismo colocam parâmetros para o corpo, mas o corpo é apenas um instrumento para movimentar e utilizar para tarefas diárias, ex.: (malhar, estudar, andar, viver)." O Participante 24 reforça o discurso anterior: "Corpo é uma ferramenta que utilizamos diariamente para ajudar nas atividades diárias".

Percebe-se, nos discursos, o sentido instrumental do corpo, com forte relação ao entendimento de corpo físico, somático, como mais um objeto da natureza. Isto posto, remete a Cardinalli (2003), referenciado às distinções que Heidegger apresenta entre corpo e corporeidade, e diz não ser mais possível hoje conceituar apenas "[...] o corpo fisicamente presente, mensurável, constituído de órgãos e com seus contornos limitados à epiderme" (p. 251).

Esta forma de entender o corpo como um objeto útil para a realização de tarefas também encontra-se presente nos discursos referentes à Unidade de Significado "Cartão de visita / Estética", apresentada mais à frente.

\section{O corpo como "Meio de expressão"}

O corpo como "Meio de expressão" foi caracterizado em quatro discursos. O mais interessante é o discurso do Participante 1: "O Corpo é físico, palpável, foi criado de alguma forma que nos traz a satisfação de movimentos, expressa sentimentos, ter longevidade, saúde, carisma, alegria de sentir cada movimento, seja de correr, saltar, deitar, ou seja, o corpo é uma obra-prima criada por (Deus)". Neste discurso, pode-se comprovar a divergência, já que o mesmo participante também considera o corpo como uma estrutura física (anatômica) e, igualmente, como uma construção divina. A Participante 26 é objetiva: "É o que somos, nosso jeito de ser". 
O corpo como "Templo, morada, casa"

O corpo percebido como "Templo, morada, casa", sem qualquer menção à religião, foi manifesto em três discursos. O Participante 28 afirma: "O nosso corpo é a nossa 'casa ambulante'. O corpo da pessoa é o reflexo do seu estilo de vida, por isso devemos cuidar bem de nossos corpos, como cuidamos das coisas que amamos". A Participante 20 assevera: "É um templo. Minha morada. $\mathrm{O}$ que me conduz pelos caminhos que escolho seguir. $\mathrm{O}$ que me permite viver plenamente e realizar sonhos, projetos". Este último discurso, por exemplo, mostra que alguns alunos concluintes parecem estar em momento de transição entre a velha concepção de corpo e a possibilidade de caminhar para novos patamares.

\section{O corpo como "Cartão de visita / Estética"}

A utilização do corpo como "Cartão de visita / Estética" pelos alunos concluintes é algo que faz referência ao sentido de corpo como modelo corporal e marketing para sedução profissional do cliente e que pode ser evidenciado em três discursos. O Participante 5 declara: "Corpo para mim é o meu cartão de visita quando eu me apresentar para o meu aluno. E, para mim, é muito importante sim esse aspecto para ter uma boa impressão para meus clientes. E por isso cuido bem do meu corpo em questão estética e saúde mesmo, pois para mim, é muito importante". E o Participante 17 esclarece: "Corpo para mim é o meu instrumento de trabalho, é o meu cartão de visitas, é o meu desafio, corpo é a superação, e a autoestima é a melhor forma de expressão, é o meu ganha-pão". Por sua vez, a Participante 9 faz uma monossilábica, ainda que importante, menção à palavra "estética": "É um instrumento de uso do ser humano, arte, estética, dependência dos afazeres do dia a dia".

\section{O corpo como "Arte"}

Tão somente com uma aparição, o entendimento do corpo como "Arte" surge no discurso da Participante 9: "É um instrumento de uso do ser humano, arte, estética, dependência dos afazeres do dia a dia". Neste discurso, é possível notar duas divergências, já que esta participante também argumenta que corpo é um "instrumento para atividades diárias", e que corpo é "estética" no intuito de modelo corporal, inclusive estando estas mais fortes que a própria menção à Arte, que, neste caso, parece estar fora de contexto. 


\section{O corpo como "Instrumento de aprendizagem"}

Na contramão dos resultados, encontra-se o Participante 25, que considera corpo como um "Instrumento de aprendizagem", que obteve somente uma citação.

Levando as nove unidades de significado que vertebram os discursos dos alunos concluintes para o mundo da formação profissional do Bacharelado em Educação Física, presente há mais de trinta anos no Brasil, pode-se visualizar alguns pontos que merecem análise.

O currículo da IES analisada neste artigo seguiu a Resolução n- 7/2004 (Conselho Nacional de Educação, 2004), que foi estruturada em dois grandes momentos: formação ampliada e formação específica.

$\mathrm{Na}$ formação ampliada propõe-se abranger as seguintes dimensões de conhecimento: “a) Relação ser humano-sociedade; b) Biologia do corpo humano; c) Produção do conhecimento científico e tecnológico" (p. 18). Já a formação específica, destinada aos conhecimentos identificadores da Educação Física, contempla as dimensões: "a) Culturais do movimento humano; b) Técnico-instrumental; c) Didático-pedagógico" (Conselho Nacional de Educação, 2004, p. 18).

Interessante observar, quando se analisa o fenômeno corpo/corporeidade, que a Resolução n- 7/2004 (Conselho Nacional de Educação, 2004) apenas deixa claro o entendimento de corpo no sentido biológico, importante, sem dúvida, mas insuficiente para a possibilidade da formação de atitude de corporeidade.

As unidades de significado com maior incidência incluem a concepção biológica da Resolução n- 7/2004 no que tange à compreensão de corpo dos participantes desta pesquisa.

Os resultados identificados no universo do presente estudo, composto por alunos concluintes, são similares aos resultados encontrados por Lüdorf (2004), mas com um universo diferente, constituído por 15 professores da Escola de Educação Física e Desportos (EEFD) da Universidade Federal do Rio de Janeiro (UFRJ). Neste estudo, a autora investigou e discutiu como o corpo, em particular o corpo estético, foi tratado pelo grupo de 15 docentes no contexto da formação de professores, e uma das conclusões 
aponta para "[...] uma considerável parcela dos professores possui uma visão de corpo e de Educação Física ancorada em princípios biológicos e técnicos" (Lüdorf, 2004, p. 233).

\subsection{Discussão da Pergunta 2}

Nesta seção, volta-se a alertar que a soma das unidades de significado da Tabela 3 não tem o percentual de 100, já que as respostas presentes nos discursos podem estar incluídas em mais de uma unidade de significado, ou, ao contrário, podem não pertencer a nenhuma unidade de significado elaborada, como são os casos dos Participantes 1, 2, 6, 10 e 22.

\section{"De acordo com o aprendido no curso universitário"}

Com um quantitativo extremamente significativo, a unidade "De acordo com o aprendido no curso universitário" prevaleceu no discurso de quase metade dos alunos concluintes (48,27\%). O relato da Participante 29 resume esta unidade: "Aplicando o que nos passam. Sabendo aproveitar todo ensinamento dado em sala de aula Teórica/Prática para que eu consiga aplicar um trabalho correto e satisfatório. Instruindo alunos em seus objetivos, tendo assim, exercícios específicos".

Vê-se, com base na alta incidência desta unidade de significado nos discursos, a importância de as matrizes curriculares dos cursos de Bacharelado em Educação Física incluírem o estudo do fenômeno corpo/corporeidade, já que praticamente a metade dos alunos concluintes utiliza o conhecimento adquirido no curso universitário para consubstanciar a sua prática.

A importância referida no parágrafo anterior se deve por constatar, como revela Moreira (2019, p. 24), que a formação profissional na área apresenta grande quantidade de componentes voltados "[...] para o corpo objetivo, e por decorrência ao corpo-objeto, manipulado, esquadrinhado, invadido", reforçando a necessidade do domínio de conhecimentos "[...] necessários para a vida sob os aspectos da fisiologia, da anatomia, da biologia, da biodinâmica [...]" (p. 24). Há que se oferecer um contraponto a essa visão hegemônica.

Isto corrobora com a preocupação de Merleau-Ponty (2004), quando este tece críticas ao mundo cientíico, pressuposto básico da formação profissional também em Educação Física: 
A ciência manipula as coisas e renuncia habitá-las. Estabelece modelos internos delas e, operando sobre esses índices ou variáveis as transformações permitidas por sua definição, só de longe em longe se confronta com o mundo real. Ela é, sempre foi, esse pensamento admiravelmente ativo, engenhoso, desenvolvo, esse parti pris de tratar todo ser como "objeto em geral", isto é, ao mesmo tempo como se ele nada fosse para nós e estivesse no entanto predestinado aos nossos artifícios (Merleau-Ponty, 2004, p. 13, grifo do autor).

"Ética"

Oito alunos concluintes citaram a unidade de significado "Ética" em seus discursos, colocando-a como a segunda em termos quantitativos (27,58\%). Observe-se o que relatou o Participante 13: "Com ética e profissionalismo, sempre procurando atualizar e buscando mais conhecimentos".

No discurso dos alunos foi mencionada a ética profissional, mas é evidente que o ser humano não ético jamais será um profissional ético, daí a conclusão de mera instrumentalização do conceito.

\section{"De acordo com os objetivos do aluno/cliente"}

Considerar os objetivos do aluno/cliente é necessário, apesar de outros elementos também merecerem atenção. Esta unidade foi a terceira em termos de presença (com 17,24\%). O Participante 28 menciona: "Ajudando o cliente a alcançar seu objetivo".

\section{"Segurança / Evitando lesões"}

A segurança é um tópico que sempre deve ser levado em consideração em qualquer prática corporal. Esta unidade de significado foi registrada no discurso de quatro participantes.

\section{"Responsabilidade"}

Os Participantes 8, 16 e 28 mencionaram a responsabilidade como fator essencial para desenvolver as suas aulas. É interessante notar que estes mesmos participantes fizeram, em seus discursos, menção à questão da segurança, mesmo sendo elementos díspares. 
"De forma enérgica / Dando bronca"

É intrigante observar expressões como "de forma enérgica" ou "dar bronca" no discurso de dois futuros profissionais no que diz respeito à referida unidade de significado. O Participante 15 assevera: "De forma enérgica, demonstrando os exercícios propostos e instruindo verbalmente. Da mesma que aprendi na graduação".

"De acordo com as necessidades do aluno/cliente"

A unidade "De acordo com as necessidades do aluno/cliente" foi considerada incipiente, registrada em apenas um participante (3,44\%). Trata-se de uma questão premente que merecia maior atenção por parte dos alunos concluintes, afinal de contas, é fundamental desenvolver um trabalho pautado nas necessidades, nas carências das pessoas.

Um último fato a ser discutido é o referente às características dos participantes da pesquisa, já que, entre os 29 alunos concluintes do Bacharelado em Educação Física, três eram licenciados na área (Participantes 3, 14 e 18). Tal aspecto poderia causar alguma diferença nos resultados? Sim. Não obstante, não se constatou nenhuma diferença significativa nos discursos destes três participantes em relação aos demais.

\section{Considerações finais e aportes à área da Educação Física}

Em face da confirmação dos problemas formulados e da resposta aos objetivos do presente estudo, fica patente que o sentido de corpo, no entendimento da maioria dos alunos concluintes do Bacharelado em Educação Física, é calcado numa visão tradicional e no modelo cartesiano, permeado por uma concepção dualista de corpo/mente, com ênfase no paradigma biologicista e visão mecanicista. As unidades de significado estabelecidas nos discursos provam tudo isso, já que foi possível verificar que o corpo foi compreendido pelo viés anatomofisiológico, de soma de partes sobre partes, e, igualmente, associado à máquina. Estas constatações são corroboradas pelo estudo de Silva, Lüdorf, Silva e Oliveira (2009), que investigaram 103 alunos de primeiro e de últimos períodos de Licenciatura em Educação Física de uma universidade pública do Estado do Rio de Janeiro: 
Conclui-se que os acadêmicos do curso pesquisado apresentaram uma visão de corpo ainda marcada por uma tendência biologizante, como não poderia deixar de ser, dada a construção histórica da Educação Física, no entanto, surgiram importantes indícios de modificação ou ampliação dessa concepção, devido, possivelmente, sem exaurir outros fatores complexos e interligados, ao arcabouço teórico derivado das disciplinas do curso de Licenciatura ora pesquisado (p. 122).

Ainda com relação às unidades de significado com importante incidência, a presente pesquisa comprovou, nos discursos de muitos alunos, uma associação do corpo à esfera da divindade, do espiritual, da religião e, também, sua integração à questão do utilitarismo.

Os resultados encontrados são preocupantes, considerando o fato de se constatar que a maioria dos alunos concluintes ainda está atada a uma concepção de corpo-objeto, caracterizado em sua fragmentação num mundo de concepção mecânica (Nóbrega, 2010).

Talvez isto mostre, em certo sentido, que os trabalhos produzidos na Educação Física que enfocam o corpo-sujeito não têm tido repercussão em alguns cursos de formação profissional na área, demandando maior esforço acadêmico para alterar a situação. Há, sem dúvida, uma necessidade de alterar e/ou equilibrar este quadro.

Esse panorama sinaliza para a necessidade de considerar, nos cursos de Bacharelado em Educação Física, o ensino da corporeidade, fator importante para (re)significar o conceito e a atitude perante o vivenciar do corpo. Ser corporeidade exige mudança de paradigma no conhecimento e no trato com o corpo do aluno/cliente.

Será que a Educação Física está preparada para enfrentar esse desafio? O profissional bacharel, em sua atividade diária de ensinar o conhecimento e a prática da execução dos exercícios físicos, deve se ater ao sentido de corpo-sujeito, abandonando a perspectiva de corpo-objeto a ser manipulado ou simplesmente "malhado". Fica aqui uma inquietação: professores, pesquisadores e gestores de cursos universitários em Educação Física estão realmente contribuindo para essa formação mais humana dos futuros profissionais da área? 
Que os argumentos apresentados nesta pesquisa possam alertar para a importância da aprendizagem do fenômeno corpo/corporeidade, além de fomentar uma mudança de um paradigma biologicista para uma concepção humanista em relação ao trato com o corpo!

\section{Referências}

Aranda, R. A., Pereira, A. M., Palma, J. A. \& Palma, A. P. T. V. (2012). A concepção de corpo dos estudantes de graduação em educação física, Motriz: Revista de Educação Física, 18(4), 735-747, out./dez. Disponível em https://bit.ly/2ZFDySe

Bardin, L. (1977). Análise de conteúdo. Lisboa: Edições 70.

Bruyne, P. de, Herman, J. \& Schoutheete, M. de. (1991). Dinâmica da pesquisa em ciências sociais: Os pólos da prática metodológica. (5ª ed.). Rio de Janeiro: Francisco Alves.

Caminha, I. de O. (2019). Eu, a educação física e Merleau-Ponty. Em T. P. da Nóbrega \& I. de O. Caminha (Orgs.), Merleau-Ponty e a educação física (57-67). São Paulo: LiberArs.

Cardinalli, I. E. (2003). O "corpo" segundo Heidegger e Boss. Em D. S. P. de Castro, J. D. Piccino, R. de S. Josgrilberg \& T. A. Goto (Orgs.), Corpo e existência (249-254). São Paulo: Umesp-Fenpec.

Conselho Federal de Educação (Brasil). (1987). Resolução n 3, de 16 de junho de 1987. Fixa os mínimos de conteúdo e duração a serem observados nos cursos de graduação em Educação Física (Bacharelado e/ou Licenciatura Plena). Diário Oficial: República Federativa do Brasil: seção 1, Brasília, DF, ano 322(172), 14682, 10 set.

Conselho Nacional de Educação (Brasil). (2004). Câmara de Educação Superior. Resolução $\mathrm{n}^{\circ} 7$, de 31 de março de 2004. Institui as Diretrizes Curriculares Nacionais para os cursos de graduação em Educação Física, em nível superior de graduação plena. Diário Oficial da União: seção 1, Brasília, DF, ano 141(65), 18-19, 5 abr.

Conselho Nacional de Educação (Brasil). (2007). Câmara de Educação Superior. Resolução $n^{\circ} 7$, de 4 de outubro de 2007. Altera o $\S 3^{\circ}$ do art. 10 da Resolução CNE/CES ${ }^{\circ}$ $7 / 2004$, que institui as Diretrizes Curriculares Nacionais para os cursos de graduação em Educação Física, em nível superior de graduação plena. Diário Oficial da União: seção 1, Brasília, DF, ano 144(193), 49, 5 out.

Conselho Nacional de Educação (Brasil). (2018). Câmara de Educação Superior. Resolução n 6, de 18 de dezembro de 2018. Institui Diretrizes Curriculares Nacionais dos Cursos de Graduação em Educação Física e dá outras providências. Diário Oficial da União: seção 1, Brasília, DF, ano 155(243), 48-49, 19 dez.

España. Ministerio de Ciencia, Innovación y Universidades. (2018). Resolución nº 12774, de 18 de septiembre de 2018. Se establecen recomendaciones para la propuesta por las universidades de memorias de verificación del título oficial de Grado en Ciencias de la Actividad Física y del Deporte. Boletín Oficial del Estado: sec. III, [Madrid], n. 228, p. 91209-91217, 20 sept.

Gallo, S. (2006). Corpo ativo e filosofia. Em W. W. Moreira (Org.), Século XXI: A era do corpo ativo (9-30). Campinas: Papirus. 
Gallo, S. \& Zeppini, P. S. (2016). "O que pode um corpo?": perspectivas filosóficas para a corporeidade. Em W. W. Moreira \& V. L. Nista-Piccolo (Orgs.), Educação física e esporte no século XXI (107-131). Campinas: Papirus.

Giorgi, A. (1978). A psicologia como ciência humana: Uma abordagem de base fenomenológica. Belo Horizonte: Interlivros.

Inforsato, E. do C. (2006). A educação entre o controle e a libertação do corpo. Em W. W. Moreira (Org.), Século XXI: A era do corpo ativo (91-108). Campinas: Papirus.

Lüdorf, S. M. A. (2004). Do corpo design à educação sociocorporal: O corpo na formação de professores de educação física (Tese de doutorado não publicada). Faculdade de Educação, Centro de Filosofia e Ciências Humanas, Universidade Federal do Rio de Janeiro, Brasil.

Martins, J. \& Bicudo, M. A. V. (1989). A pesquisa qualitativa em psicologia: Fundamentos e recursos básicos. São Paulo: Ed. Moraes: EDUC - Ed. da PUC-SP.

Medina, J. P. S. (1987). O brasileiro e seu corpo. Campinas: Papirus.

Medina, J. P. S. (2001). Aeducaçãofísica cuida do corpo... E "mente”. (15ª ed). Campinas: Papirus.

Merleau-Ponty, M. (1990). O primado da percepção e suas conseqüências filosóficas. Campinas: Papirus.

Merleau-Ponty, M. (1991). Signos. São Paulo: Martins Fontes.

Merleau-Ponty, M. (2004). O olho e o espírito. São Paulo: Cosac \& Naify.

Merleau-Ponty, M. (2007). O visível e o invisível. São Paulo: Perspectiva.

Merleau-Ponty, M. (2018). Fenomenologia da percepção. Tradução Carlos Alberto Ribeiro de Moura. ( $\left.5^{\mathrm{a}} \mathrm{ed}\right)$. São Paulo: WMF Martins Fontes. (Biblioteca do pensamento moderno).

Morais, J. F. R. de. (2014). Consciência corporal e dimensionamento do futuro. Em W. W. Moreira (org.), Educação física \& esportes: Perspectivas para o século XXI (71-87). (17a ed). Campinas: Papirus.

Moreira, W. W. (1995). Corpo presente num olhar panorâmico. Em W. W. Moreira (Org.), Corpo pressente (17-36). Campinas: Papirus. (Coleção Corpo e motricidade).

Moreira, W. W. (2019). Merleau-Ponty na sala de aula e na beira do campo: Contribuições para a área da educação física/esportes. Em: T. P. da Nóbrega \& I. de O. Caminha (Orgs.), Merleau-Ponty e a educação física (21-37). São Paulo: Editora LiberArs.

Moreira, W. W. \& Simões, R. (2016). Educação física, esporte e corporeidade: Associação indispensável. Em W. W. Moreira \& V. L. Nista-Piccolo (Orgs.), Educação física e esporte no século XXI (133-149). Campinas: Papirus

Moreira, W., Simões, R. \& Porto, E. (2005). Análise de conteúdo: Técnica de elaboração e análise de unidades de significado. Revista Brasileira de Ciência e Movimento, 13(4), 107-114.

Nóbrega, T. P. da. (2010). Uma fenomenologia do corpo. São Paulo: Livraria da Física.

Oliveira, V. M. de. (1987). Ginástica para a alma, música para o corpo. Em V. M. de Oliveira (Org.), Fundamentos pedagógicos educação física: Flexões e reflexões (62-73). Rio de Janeiro: Ao Livro Técnico. (Coleção Educação física. Série Aperfeiçoamento. Fundamentos pedagógicos, 2). 
Rouanet, S. P. (2003). O homem-máquina hoje. Em A. Novaes (Org.), O homem-máquina: A ciência manipula o corpo (37-64). São Paulo: Companhia das Letras.

Santin, S. (2014). Perspectivas na visão da corporeidade. Em W. W. Moreira (Org.), Educaçãofísica \& esportes: Perspectivas para o século XXI (51-69). (17ª ed). Campinas: Papirus.

Silva, A. C., Lüdorf, S. M. A., Silva, F. A. G. da \& Oliveira, A. P. de. (2009). A visão de corpo na perspectiva de graduandos em educação física: Fragmentada ou integrada? Movimento, 15(3), 109-126, jul./set.

Silva, J. B. F. da. (1987). Rumo ao universo... do corpo. Em V. M. de Oliveira (Org.), Fundamentos pedagógicos educação física: Flexões e reflexões (48-54). Rio de Janeiro: Ao Livro Técnico. (Coleção Educação física. Série Aperfeiçoamento. Fundamentos pedagógicos, 2).

Souza, S. G., Schmidt, A., Santo, M. G. \& Montalvão, V. de O. (2011). Visão de corpo dos graduandos em bacharelado do curso de Educação Física de uma instituição de ensino superior privada de Goiânia. Lecturas: Educación Física y Deportes, 15(153), fev. Disponível em https://bit.ly/3kcZ3TN 